This document is the accepted manuscript version of the following article:

Zhong, P., Wyrzykowski, M., Toropovs, N., Li, L., Liu, J., \& Lura, P. (2019). Interna1

curing with superabsorbent polymers of different chemical structures. Cement and

Concrete Research, 123, 105789 (11 pp.). https://doi.org/10.1016/j.cemconres.2019.105789

This manuscript version is made available under the CC-BY-NC-ND 4.0

license http://creativecommons.org/licenses/by-nc-nd/4.0/

\title{
Internal curing with superabsorbent polymers of different chemical
}

\section{structures}

Peihua Zhong ${ }^{1 *}$, Mateusz Wyrzykowski ${ }^{2}$, Nikolajs Toropovs ${ }^{2}$, Lei $\mathrm{Li}^{3}$, Jiaping Liu ${ }^{1,3,4,5}$, Pietro Lura ${ }^{2,6}$

1. School of Material Science and Engineering, Southeast University, Nanjing 211189, China

2. Empa, Swiss Federal Laboratories for Materials Science and Technology, Überlandstrasse 129, 8600 Dübendorf, Switzerland

3. Jiangsu Sobute New Materials Co., Ltd., Nanjing 211103, China

4. State Key Laboratory of High Performance Civil Engineering Materials, Nanjing 211103, China

5. Jiangsu Key Laboratory of Construction Materials, Nanjing 211189, China

6. Institute for Building Materials (IfB), ETH Zurich, 8092 Zurich, Switzerland

* corresponding author: peihua_zhong@foxmail.com

\section{Abstract:}

This study investigates the absorption behavior of superabsorbent polymer (SAP) with different chemical structures and their effect on cement hydration, early-age autogenous shrinkage and mechanical properties of cement paste. SAP with high density of anionic functional groups absorbed the cement pore solution quickly, and then released it because the anionic groups on the network of SAP complexed with multivalent cations in the pore solution (e.g., $\mathrm{Ca}^{2+}$ ). Much less release was measured for SAP with low density of anionic groups. Furthermore, SAP with either both anionic and cationic groups or with only non-ionic groups did not release the liquid. Despite their different behavior in solutions, all SAP were able to counteract autogenous shrinkage. SAP with either both ionic groups or high density of anionic groups showed excellent internal curing effect. The internal curing had no 
negative effect on the compressive strength of the paste when the total cement-to-water ratio was considered.

Keywords: Superabsorbent polymers; chemical structure; absorption; autogenous shrinkage; mechanical properties

\section{Introduction}

High performance concrete (HPC) (also known as high strength concrete, HSC) has become popular due to superior mechanical and durability properties [1], in particular for applications in extreme environmental conditions $[2,3]$. In HPC, the water-to-cement ratio (w/c) is kept low to reduce the porosity and improve the durability, with the unintended consequence that the amount of water is insufficient for complete cement hydration [4]. The shortage of water and the fine pores result in a pronounced decrease in relative humidity $(\mathrm{RH})$ within the pore system [5], which is accompanied by increasing pore pressure and autogenous shrinkage [6]. The high autogenous shrinkage and relatively low tensile strength especially at early ages result in macroscopic cracks in restrained concrete members [7], which can substantially decrease the service life of structures made with HPC.

Conventional methods for curing of concrete, such as external water curing, cannot contribute substantially to mitigating the autogenous shrinkage of concrete with low w/c. In fact, since the microstructure of typical HPC is very dense even at early age, it does not allow sufficiently rapid transport of curing water into the interior of concrete members, beyond a few $\mathrm{mm}$ from the surface. Internal curing is considered as an effective method to maintain high relative humidity $(\mathrm{RH})$ and mitigate self-desiccation of HPC [8-10]. Autogenous shrinkage can be mitigated by introducing into the concrete materials with high water storage capacity, referred to as internal curing agents [11], which release the stored water into the concrete matrix during self-desiccation. Lightweight aggregates (LWA) with open porosity are a class of internal curing agents that can be effective at reducing or eliminating autogenous shrinkage [12-14]. However, incorporation of LWA can compromise the final compressive strength of concrete through the introduction of voids and flaws in the cured concrete. In fact, more porosity is 
typically added than the minimum needed to store water for internal curing and hence the LWA with poor mechanical properties end up occupying a considerable volume of concrete [15]. In addition, the amount of internal curing water stored in the LWA is difficult to control for a number of reasons, including: a) the absorption may vary between different batches; b) it is difficult to measure absorption in saturated surface dry conditions accurately; c) it is also difficult to avoid water release during mixing or pumping. Besides, not all the pores of the LWA can be filled by water and not all the water stored in the LWA can be used for internal curing $[11,12,16]$. Superabsorbent polymers (SAP) are another most commonly used internal curing agent [17-19]. SAP can absorb water and solutions up to thousands of times their dry weight because of their hydrophilic network structures consisting of cross-linked polyelectrolytes [20]. SAP also exhibit superior desorption capacity compared to other candidate internal curing materials $[13,14,16,17]$. Differently from LWA, which usually need to be pre-saturated [12-14], SAP are usually employed as a dry concrete admixture and take up water during the mixing process. The use of SAP permits moreover free design of the shape and size of the formed voids [17].

SAP particles are polymer hydrogels composed of polyelectrolyte chains which are covalently crosslinked to form a three-dimensional polymer network [20]. Driven by osmotic pressure and water affinity, dry SAP particles swell when in contact with water (or aqueous solutions) [21]. Osmotic pressure results from the formation of a chemical potential gradient in the system due to the relatively high concentration of ions within the network of the SAP compared to the external environment [22]. The most common SAP used as internal curing agent in concrete are covalently cross-linked copolymers of acrylic acid and acrylamide. They are chemically stable and able to swell in the strongly alkaline cement pore solution [23]. The carboxylic acid groups of the acrylic acid monomer will deprotonate at $\mathrm{pH}>5$ (partially neutralized acrylic acid sometimes is directly used for synthesis), whereas the amide groups of the acrylamide monomer are partially hydrolyzed to form anionic carboxylic groups along the polymer chain when the $\mathrm{pH}$ is higher than about $12[22,24]$. During the hydration process of cement, multiple ions are released into the pore solution, such as $\mathrm{K}^{+}, \mathrm{Na}^{+}, \mathrm{Ca}^{2+}, \mathrm{SO}_{4}{ }^{2-}$ and $\mathrm{OH}^{-}[25,26]$. The swelling of SAP in pore solution is substantially lower compared to deionized water [22, 27-29]. Lower absorption in cement filtrate compared to a $0.1 \mathrm{M} \mathrm{NaOH}$ solution with similar $\mathrm{pH}(\sim 12)$ was observed in [30]. This phenomenon, commonly observed in the swelling of ionic hydrogels, is often attributed to 
a charge screening effect of the additional cations [24, 28]. This screening reduces the electrostatic repulsion and leads to a decreased osmotic pressure between the hydrogel network and the external solution [31]. Besides, the presence of $\mathrm{Ca}^{2+}$ ions in the pore solution has a strong impact on the absorption kinetics of the SAP in relation to the anionic group density of the SAP. $\mathrm{Ca}^{2+}$ will in fact complex with carboxylate groups from the molecular chains of the SAP, forming additional crosslinks which restrain the movement of the chains in the polymer $[22,25,26,32]$. The absorption of SAP particles in cement paste, mortar or concrete is even smaller than in artificial pore solution, likely because of the resistance to swelling exerted by the surrounding material [29] or due to the mixing process. Besides, the composition of the pore fluid within cement pastes or concrete will change with cement hydration [33,34], contrary to artificial pore solution. Observations of SAP absorption in cement pastes indicate that the total absorption may be about half the amount for synthetic pore solution [18].

Only few systematic studies have been devoted to the effect of SAP synthesis on their performance as internal curing agents. Jensen and Hansen [18] reported that suspension-polymerized SAP (dry particle sizes $\sim 200 \mu \mathrm{m}$ ) had about half the absorption in synthetic pore fluid compared to solution-polymerized SAP (dry particles sizes 125-250 $\mu \mathrm{m}$ ). According to Siriwatwechakul et al. [30], solution-polymerized SAP had slower absorption in water than suspension polymerized SAP. Even though the authors reported that both SAP types had similar chemistry (polyacryalminde structure cross-linked with methylene-bis-acrylamide) and had similar sizes $(<100 \mu \mathrm{m})$, it should be stressed that in fact different physical properties (shape, sizes and surface characteristics) and some differences in the chemistry could be responsible for the different absorption behavior. In a further study by the same group [35], it was reported that solution-polymerized SAP resulted in higher early-age strength concrete than suspensionpolymerized SAP.

Schröfl et al. showed that SAP with high density of anionic functional groups (high acrylic acid, AA) took up cement pore solution quickly, but released a large part of it subsequently [28]. The covalent cross-linking density had no pronounced influence on the behavior of such SAP. The presence of $\mathrm{Ca}^{2+}$ ions in the alkaline solutions had a strong influence on the absorption and desorption behavior [28]. Zhu et al. synthesized a series of poly (sodium acrylate-acrylamide) copolymer hydrogels in which the 
concentration of covalent crosslinks and anionic groups within the polymer network varied systematically. The results showed that cations $\left(\mathrm{Na}^{+}, \mathrm{Ca}^{2+}, \mathrm{Al}^{3+}\right)$ have negative impacts on the swelling capacity and kinetics of PANa-PAM hydrogels, and increased covalent crosslinking density in PANaPAM hydrogel samples resulted in a decreased equilibrium swelling ratio for samples immersed in water or solutions containing $\mathrm{Na}^{+}$ions [22]. Besides, multivalent cations in the pore solution (e.g., $\mathrm{Ca}^{2+}$ ) will complex with the carboxylic groups, thereby reducing significantly the SAP absorption $[28,36]$. The absorption behavior of SAP with a small amount of cationic monomer will be especially affected by multivalent cations [37, 38].

According to Schröfl and co-workers [28, 39], SAP that show fast liquid release due to high AA can only mitigate autogenous shrinkage at very early ages. After the initial fast release, the positive effect of these SAP disappears and the rate of autogenous shrinkage becomes the same as in mortars without SAP. However, in a later work by Krafcik and Erk [32], SAP with high AA (which also showed relatively fast release of absorbed pore solution) were found to be the most efficient type for reducing autogenous shrinkage of mortars. According to Snoeck et al., SAP with high absorption and large particle size are not ideal for mitigating autogenous shrinkage [40].

The motivation of this study is to provide a better understanding of the effect of SAP chemistry on their performance and eventually their effect on the properties of internally cured cementitious materials. To this end, the influence of three main chemical characteristics of the SAP is investigated; these include: a) the concentration of anionic groups, b) the degree of cross-linking and c) the type of functional groups present on the network. A novel SAP (zwitterionic SAP) class with both anionic and cationic monomers was also used for internal curing. The absorption of SAP was first measured over time in both deionized water and cement filtrates. In addition, the influence of the chemical characteristics of the SAP on cement hydration, autogenous deformation and compressive strength were also investigated.

\section{Materials and methods}

\subsection{Superabsorbent polymer}

The SAP samples had as main monomers acrylic acid (AA, Sinopharm, Shanghai, China), acrylamide (AM, Aladdin, Shanghai, China) and methacrylamidopropyltrimethylammonium chloride (MAPTAC, 

as crosslinking agent $[20,23]$. Sodium hydroxide $(\mathrm{NaOH}$, Sinopharm, Shanghai, China) was used to neutralize AA. Potassium persulfate $\left(\mathrm{K}_{2} \mathrm{~S}_{2} \mathrm{O}_{8}\right.$, Sinopharm, Shanghai, China) was used as initiator. Span80 and Span85 (Sinopharm, Shanghai, China) were used as dispersant. Cyclohexane was used as the hydrocarbon phase. Table 1 provides information on the monomer composition of the SAP. All SAP are in the form of spherical particles produced using the inverse suspension polymerisation technique (see optical microscope image, Fig. 1) [20, 41, 42]. A total of eight types of SAP were synthesized and labelled based on the chemical composition. The first letters in the label refer to the SAP types: A refers to the anionic SAP, $\mathrm{N}$ refers to the AM-based SAP and $\mathrm{Z}$ refers to the zwitterionic SAP. The number after A refers to the ratio between AA and AM (e.g., A37 indicates an anionic SAP that contains 30\% AA and 70\% AM monomers). The number 5 after the underline indicates that the crosslinking density is increased by 5 times compared to the reference. Anionic SAP was synthesized with anionic monomers AA $(80 \%$ molar ratio neutralized by $\mathrm{NaOH})$ and $\mathrm{AM}$. As AA is neutralized before polymerization (to repeat units.

In a $2 \mathrm{~L}$, three-necked, round-bottomed flask with a reflux and stirrer, cyclohexane, Span 80 and Span85 were added, which were heated to constant $45^{\circ} \mathrm{C}$ in a water bath. Since the inverse suspension polymerisaton technique was used, the cyclohexane to water phase (all monomer aqueous solution) ratio 
was 1.5. The concentration of dispersant in cyclohexane was $0.5 \mathrm{wt} \%$. An acrylic acid aqueous solution was neutralized by a sodium hydroxide aqueous solution, and the neutralization was $80 \%$ (molar ratio). The initiator solution was obtained by separately dissolving $\mathrm{K}_{2} \mathrm{~S}_{2} \mathrm{O}_{8}$ in concentration equal to $0.1 \%$ molar ratio of all monomers. Aqueous solutions of AM, MAPTAC and MBA were also obtained by separately dissolving each monomer according to the composition in Table 1. All aqueous solutions of monomers, initiator and crosslinking agent were mixed after being fully dissolved at room temperature, and the obtained mixture was added dropwise into the flask with vigorous stirring. The stirrer speed was maintained at $160 \mathrm{rpm}$. The reaction was carried out under vigorous stirring for $3 \mathrm{~h}$ at $50^{\circ} \mathrm{C}$ first and then the temperature was increased by $5^{\circ} \mathrm{C}$ every second hour until $70^{\circ} \mathrm{C}$. The reaction occurred rapidly and there was a marked increase in the viscosity of the medium. For different SAP, the formation time varied from a few minutes to a few hours. All vials were allowed to rest for another $12 \mathrm{~h}$, at least, after the gel formation to ensure reaction completion. Then, the precipitates were washed with large amounts of methanol and filtered. The resulting SAP, in the form of white powder, was vacuum-dried at $60^{\circ} \mathrm{C}$. The particle size distributions of the SAP samples in the dry state were characterized by optical microscope image analysis aided with ImageJ software [45]. All SAP samples have a similar particle size distribution in the dry state and the average particle size is approximately $100-110 \mu \mathrm{m}$.

\begin{tabular}{|c|c|c|c|c|}
\hline SAP types & AA & AM & MAPTAC & $\begin{array}{c}\text { Crosslinking agent (by molar of } \\
\text { monomers) }\end{array}$ \\
\hline N & 0 & $100 \%$ & - & $0.001 \%$ (MBA) \\
\hline A37 & $30 \%$ & $70 \%$ & - & $0.001 \%$ (MBA) \\
\hline A55 & $50 \%$ & $50 \%$ & - & $0.001 \%$ (MBA) \\
\hline A73 & $70 \%$ & $30 \%$ & - & $0.001 \%$ (MBA) \\
\hline Z & $30 \%$ & $50 \%$ & $20 \%$ & $0.001 \%$ (MBA) \\
\hline N_5 & 0 & $100 \%$ & - & $0.005 \%$ (MBA) \\
\hline A37_5 & $30 \%$ & $70 \%$ & - & $0.005 \%$ (MBA) \\
\hline Z_5 & $30 \%$ & $50 \%$ & $20 \%$ & $0.005 \%$ (MBA) \\
\hline
\end{tabular}




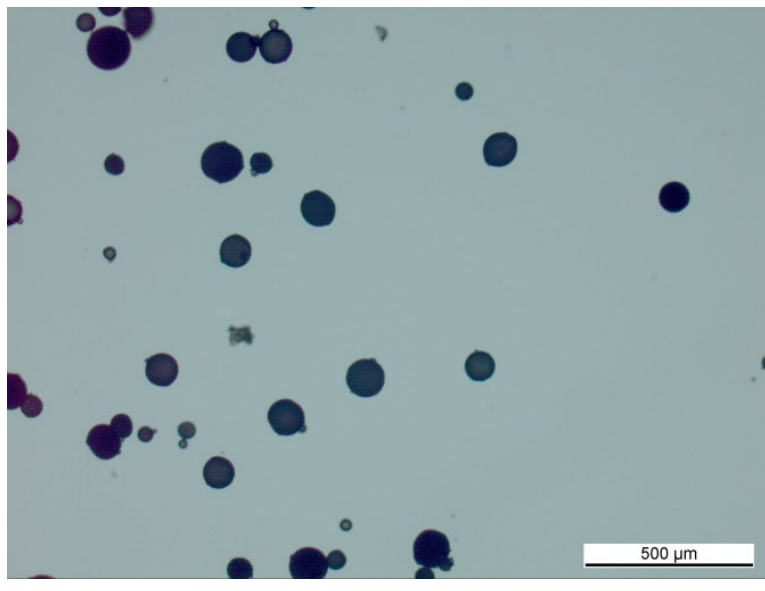

(a)

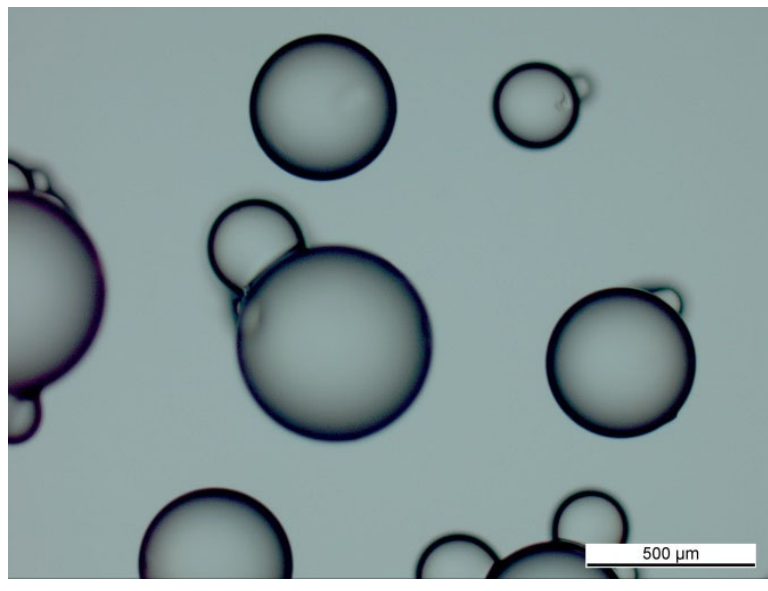

(b)

Fig. 1. Optical microscope image of A73 particles (because all different SAP types are in the form of spherical particles and look very similar, only one type of SAP is shown): a) dry state; b) water saturated. Images taken with a Sony DKC-5000 camera mounted on a Zeiss Axioplan optical microscope.

\subsection{Mix composition of cement pastes}

The cement used in this study was an ordinary Portland cement (CEM I $42.5 \mathrm{~N}$ ) by Jura Cement complying with SN EN 197-1. Deionized water was used as mixing water. A commercial polycarboxylate-based superplasticizer (PCE, Sika 20 plus N) was used for all mixtures at a dosage of $0.5 \%$ by mass of cement. The PCE was pre-dissolved in the mixing water. The mixture proportions are shown in Table 2. The $w / c$ of the reference paste $\mathrm{R}$ is 0.300 (not taking into account the water in the superplasticizer), while the entrained $w_{e} / c$ for all pastes containing SAP is 0.054 . This value was calculated according to Powers' model, see Eq. 1 below [8], as corresponding to the volume of chemical shrinkage due to cement hydration to be compensated by the entrained water, necessary to avoid selfdesiccation. The $w / c$ of the second reference paste $\mathrm{R} 1$ is 0.354 , which corresponds to the sum of the basic $w / c 0.300$ and the entrained $w_{e} / c 0.054$. Using two different reference pastes allows to distinguish the effect on hydration, autogenous deformation and strength of a mere increase in $w / c$ from that of SAP addition. It must be noticed that the absorption kinetics of SAP changed over time when immersed in cement filtrate (especially for anionic SAP, see section 3.1). In addition, the time from water addition 
during mixing to the start of the deformation measurements is about 30 min. Thus, the dosage of SAP in the pastes is calculated from the desired amount of entrained water and from the absorption capacity $(A C)$ of each SAP type in the cement filtrate at 30 min, see equation 2.

$$
S A P / C=\frac{w_{e} / c}{A C}
$$

Table 2. Mixture proportion of the paste

\begin{tabular}{|c|c|c|c|c|}
\hline & $\mathrm{w} / \mathrm{c}$ & $\mathrm{w}_{\mathrm{e}} / \mathrm{c}$ & $\mathrm{SAP}$ (by mass of cement) & PCE (by mass of cement) \\
\hline $\mathrm{R}$ & 0.300 & - & - & $0.50 \%$ \\
\hline $\mathrm{R} 1$ & 0.354 & - & - & $0.50 \%$ \\
\hline $\mathrm{N}$ & 0.300 & 0.054 & $0.42 \%$ & $0.50 \%$ \\
\hline $\mathrm{A} 37$ & 0.300 & 0.054 & $0.19 \%$ & $0.50 \%$ \\
\hline A55 & 0.300 & 0.054 & $0.20 \%$ & $0.50 \%$ \\
\hline A73 & 0.300 & 0.054 & $0.19 \%$ & $0.50 \%$ \\
\hline Z & 0.300 & 0.054 & $0.30 \%$ & $0.50 \%$ \\
\hline A37_5 & 0.300 & 0.054 & $0.25 \%$ & $0.50 \%$ \\
\hline N_5 & 0.300 & 0.054 & $0.47 \%$ & $0.50 \%$ \\
\hline Z_5 & 0.300 & 0.054 & $0.38 \%$ & $0.50 \%$ \\
\hline
\end{tabular}

\subsection{FTIR spectra of SAP}

The functional groups of the different SAP types were characterized by Fourier-transform infrared spectroscopy (FTIR). Attenuated total reflectance (ATR) Fourier-transform infrared spectra were collected by averaging 32 scans on a Bruker Tensor 27 FTIR spectrometer by transmittance between 500 and $4000 \mathrm{~cm}^{-1}$ at a resolution of $4 \mathrm{~cm}^{-1}$ on $\sim 3 \mathrm{mg}$ of powder. The obtained IR spectral data was 
211 preprocessed using the software package OPUS (Bruker Optics GmbH, Ettlingen, Germany). Baseline 212 correction and normalization were applied to every recorded spectrum. 
The gravimetric tea-bag method was used to evaluate the overall absorption capacity and kinetics of the SAP samples [46, 47]. As the absorption performance depends on the absorbed fluid, both deionized water and filtrate of cement slurry were used. In order to produce a sufficient amount of pore solution, a slurry with w/c of 5 was prepared and continuously and automatically stirred for 24 hours, followed by filtration of the liquid. The average mass $\left(m_{0}\right)$ of fluid absorbed by an empty tea-bag was first assessed, using ten individual tea-bags. A dry tea-bag was weighed $\left(m_{l}\right)$, followed by a dry tea-bag containing the dry SAP $\left(m_{2}\right)$. This filled tea-bag was hung in a plastic bottle filled with the test fluid (either deionized water or pore solution). The bottle was rapidly and tightly sealed with a cap to avoid carbonation and evaporation. The cap was only removed shortly for each weighing. At 1, 5, 10, 30, 60 minutes, 3 and 24 hours after the SAP/liquid contact time, the tea-bag with the hydrogel inside was removed and weighed $\left(m_{3}\right)$. Before each weighing, the tea-bag with SAP was placed on a dry cloth and gently wiped with another dry cloth for a short time (approximately $30 \mathrm{~s}$ ) to remove surplus and weakly-bound liquid. After weighing, the tea-bag containing the hydrogel was returned into the test fluid until the next time step of mass recording. Equation 3 provides the formula to calculate the absorption capacity $A C$. To ensure the reliability of the results, three individual tea-bags were measured for every SAP sample.

$$
A C=\frac{m_{3}-m_{2}-m_{0}}{m_{2}-m_{1}}
$$

\subsection{Isothermal calorimetry}

All pastes were mixed at $450 \mathrm{rpm}$ in a vacuum mixer (Twister Evolution) with about $300 \mathrm{~mL}$ mixing capacity. The heat flow was measured with a Thermometric TAM Air conduction calorimeter, capable of eight parallel measurements in eight separate measuring cells. For each specimen, about $10 \mathrm{~g}$ of freshly mixed paste were weighted into a glass vial. Duplicate specimens were prepared for each mixture. The glass vial was sealed and placed into the calorimeter and the heat flow was measured for about $72 \mathrm{~h}$. During the experiment, isothermal conditions $\left(20 \pm 0.02{ }^{\circ} \mathrm{C}\right)$ were maintained in the measuring cells. 
The hydration heat flow and the cumulative hydration heat were normalized to the cement mass in the samples.

\subsection{Autogenous deformation}

Each paste was mixed using a 5-1 Hobart mixer. First, dry cement and SAP were mixed dry for $1 \mathrm{~min}$. Next, water was slowly added and wet mixing lasted for 5 min (with an intermediate $30 \mathrm{~s}$ pause after 2 min for scraping of the mixing bowl). The corrugated tubes [48] were filled with the pastes on a vibrating table and tightly closed with plastic end plugs. All shrinkage measurements were performed on a rigid stainless-steel frame capable of accommodating 6 specimens. Each sample was fixed with a clamping device at one end, and the displacement of the free end was measured with a LDT (resolution $0.1 \mu \mathrm{m})$. The data was logged at $60 \mathrm{~s}$ intervals and the measurements lasted up to 7 days from water addition. The steel frame was immersed in a bath filled with silicone oil (Rhodorsil 47V20) for temperature regulation and to ease the sliding of the tubes on the steel frame. The oil temperature was controlled by a circulating pump and a thermostat system at $20.0 \pm 0.1{ }^{\circ} \mathrm{C}$. All measurements were run and the samples were stored in the same climate-controlled room at $19.3 \pm 0.1{ }^{\circ} \mathrm{C}$ and $70 \pm 3 \% \mathrm{RH}$. The time-zero for the autogenous shrinkage measurement was determined as the time instant when the scatter of the deformation rates of replicate samples reached a constant, low level [49].

\subsection{Mechanical properties}

The prismatic samples of dimensions $25 \times 25 \times 100 \mathrm{~mm}^{3}$ for testing flexural and compressive strength of the pastes were mixed in a vacuum mixer (Twister evolution) at $450 \mathrm{rpm}$. The vacuum mixer was employed to limit the amount of entrained air, which has a significant impact on the strength, in particular for the relatively small samples of cement paste tested here (whereas the impact on the autogenous deformation after set was assumed to be negligible). The first step of dry mixing was 1 min for all mixtures. Next, the superplasticizer pre-dissolved in the mixing water was added and mixed for $5 \mathrm{~min}$. The specimens were sealed cured at $20 \pm 0.5{ }^{\circ} \mathrm{C}$ until testing. At least 3 specimens for each mixture and age were tested. All pastes were tested at 1, 3 and 7 days from sample preparation. The flexural strength was measured first in 3-point bending, followed by compressive strength measurements on each half prism. 


\section{Results and discussion}

The FTIR spectra of the SAP with different chemical structures are presented in Fig. 2. The absorption band at 3325,3186 and $1602 \mathrm{~cm}^{-1}$ are related to the stretching and bending vibrations of N-H [50-53]. The absorption band at $2933 \mathrm{~cm}^{-1}$ corresponds to the stretching vibration of C-H [54, 55]. The absorption band at $1645 \mathrm{~cm}^{-1}$ is related to the stretching vibration of $\mathrm{C}=\mathrm{O}[54,56,57]$. The peak observed at $1562 \mathrm{~cm}^{-1}$ is associated with the $-\mathrm{COO}^{-}$group in the carboxylate anion $[54,58]$. Furthermore, the absorption peaks at 1479 and $966 \mathrm{~cm}^{-1}$ arise from $\mathrm{N}^{+}\left(\mathrm{CH}_{3}\right)_{3}$ stretching vibration $[59,60]$. For SAP N, the peaks detected at 3325,1645 and $1602 \mathrm{~cm}^{-1}$ indicate $\mathrm{N}-\mathrm{H}$ stretching, $\mathrm{C}=\mathrm{O}$ stretching and $\mathrm{N}-\mathrm{H}$ bending of the amide bands, respectively, which are characteristics of the $-\mathrm{CONH}_{2}$ group in $\mathrm{AM}[51$, 61]. For SAP A37, A55 and A73, the additional peak at $1562 \mathrm{~cm}^{-1}$ indicates the $-\mathrm{COO}^{-}$group in the carboxylate anion contained in AA/ANa [55]. New peaks at 1479 and $966 \mathrm{~cm}^{-1}$ were detected with SAP $\mathrm{Z}$, which corresponds to the $\mathrm{N}^{+}\left(\mathrm{CH}_{3}\right)_{3}$ stretching vibration in MAPTAC [59, 62]. The results indicate that the different functional groups were successfully synthesized onto the corresponding SAP types. In addition, the SAP with high crosslinking density showed similar results to the corresponding reference

280 SAP type. This is consistent with the expectation that the increasing crosslinking density should have no influence on the functional groups. 


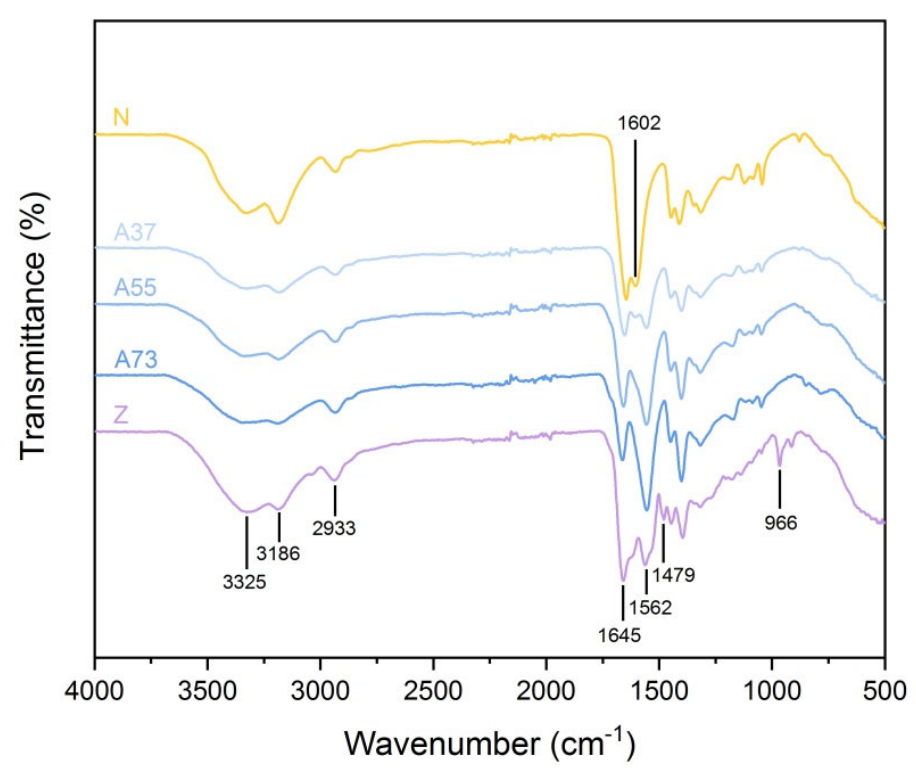

Fig. 2. FTIR spectra of different SAP types

3.2 Absorption behavior of SAP in deionized water and pore solution

The ability to absorb water, store it and release it is the essential feature of SAP to mitigate autogenous shrinkage. The main driving force for the water absorption and swelling is osmotic pressure for ionic SAP (anionic SAP and zwitterionic SAP). However, for AM-based SAP, the adsorption mechanisms are more difficult to determine. They may be the result of protonation of an amide group or the formation of a hydrogen bond between the oxygen ion of the carbonyl group and the surface hydroxyls and/ or hydrogen ion of $\mathrm{NH}_{2}$ [63-65]. To study the absorption of SAP with different chemical structures, deionized water and pore solution were considered (Figs. 3-5).

Fig. 3 shows the absorption kinetics of SAP with different chemical structures in deionized water. After a rapid initial intake of water at short times, the absorption reached an effective plateau within approximately $180 \mathrm{~min}$ for all SAP. In general, the maximum absorption and the initial absorption rate were observed to increase for SAP that contained greater concentrations of anionic group in the polymer network. With the same crosslinking density of $0.001 \%$ molar ratio, the absorption in deionized water at 24 h of SAP A37 was almost $40 \%$ of that for SAP A55 and almost $70 \%$ of that for SAP A73 (see Fig. 4.). With the same crosslinking density, ionic SAP have a larger absorption compared with AM-based 
299 SAP. The reason for this behavior is that the driving force for swelling comes from the osmotic pressure

300 (governed by the ionic groups), which is stronger than water affinity (governed by the hydrophilic

301 groups). The water affinity of PAM comes from the ability of the hydrophilic amine functionalities to

302 hydrogen bond with surrounding water molecules.

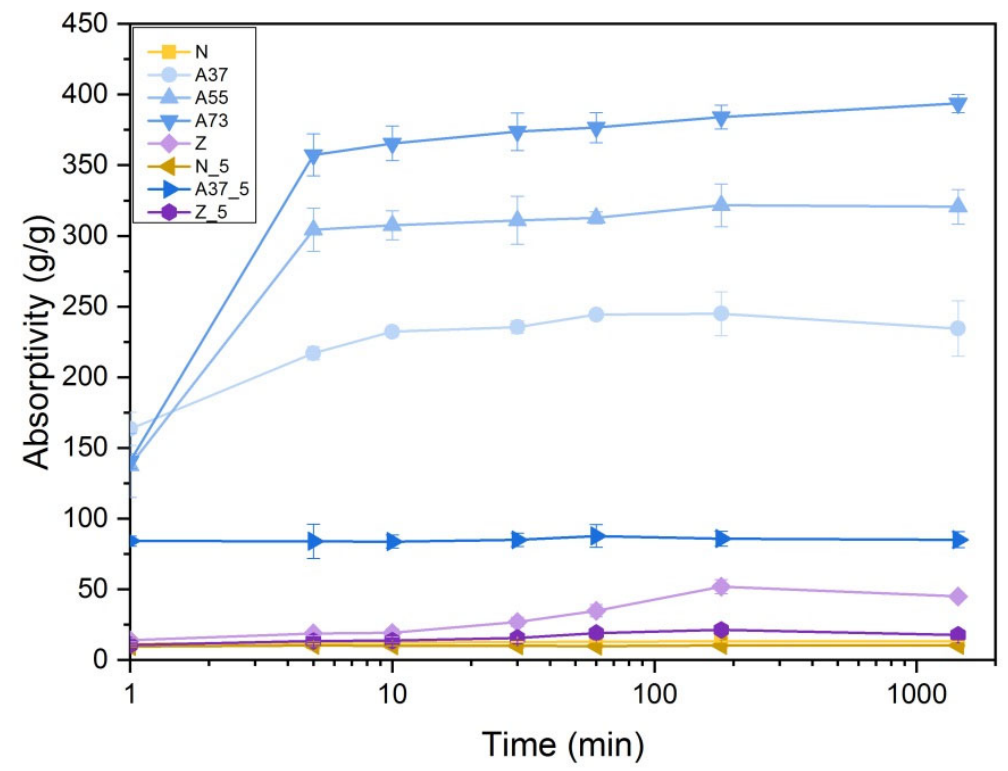

304

Fig. 3. Absorption of SAP in deionized water 


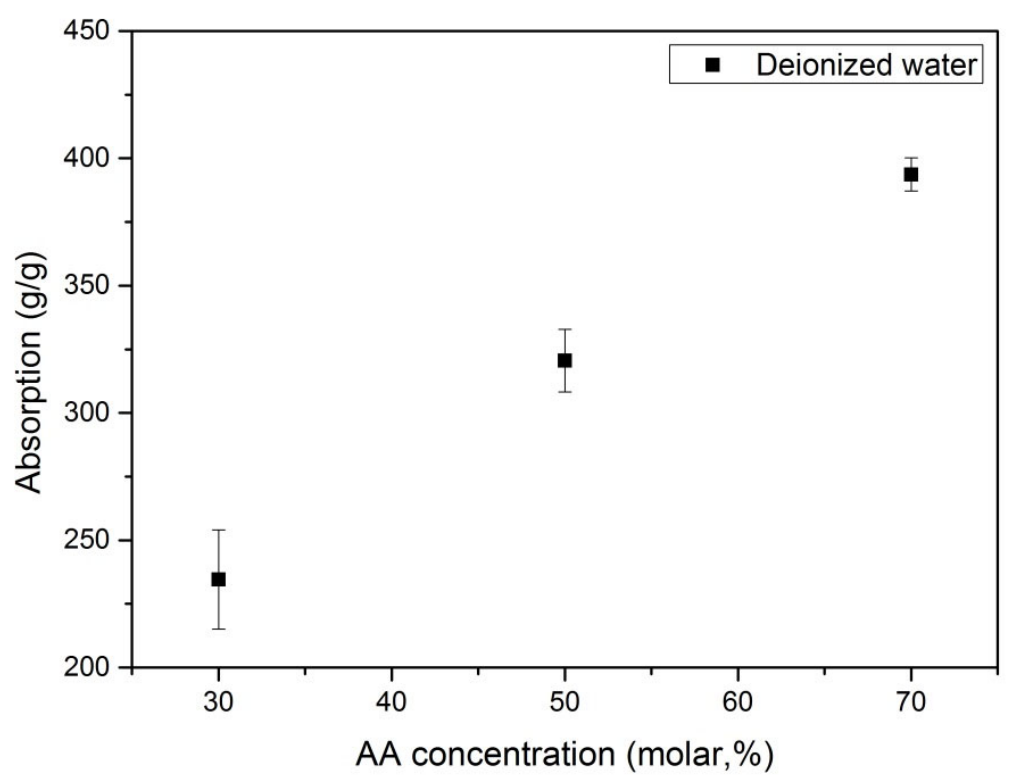

Fig. 4. Influence of AA concentration of SAP on absorption in deionized water after $24 \mathrm{~h}$.

The absorption in deionized water at $24 \mathrm{~h}$ of zwitterionic SAP $\mathrm{Z}$ is lower than for anionic SAP and higher than for AM-based SAP (see Fig. 3.). SAP A55 and SAP Z have the same molar ratio of nonionic group (50\% molar ratio), the only difference being the $20 \%$ molar ratio of anionic group replaced by cationic group in SAP Z. In other words, SAP A55 samples are composite with 50\% molar ratio AA/ANa group and 50\% molar ratio AM group. SAP Z samples are composite with $30 \%$ molar ratio AA/ANa group, 20\% molar ratio MAPTAC group and 50\% molar ratio AM group. The differences in absorption indicate that the osmotic pressure that comes from the AA/ANa group is stronger than that from the MAPTAC group. The absorption of SAP Z is even lower than that of SAP A37, which indicates that the osmotic pressure introduced by the MAPTAC group is much weaker than that of the AA/ANa group [66]. Another possible reason is that the anionic and cationic repeat groups on the zwitterionic SAP attract each other and prevent the network from expanding [67]. As introduced above, the driving force for swelling originating from osmotic pressure is stronger than that from water affinity and as a consequence the absorption of SAP Z is higher than that of SAP N.

Fig. 3 also indicates that increased crosslinking density led to decreased absorption when immersed in deionized water. This rule is valid for all samples: anionic SAP, AM-based SAP and zwitterionic SAP. 
According to Flory theory and rubber elasticity [21, 22], during the swelling process of the SAP, equilibrium is reached between the expansion force that comes from osmotic pressure or water affinity and the contraction force that originates from the network's bulk modulus [23]. Thus, as the crosslinking density increased, the bulk modulus increased as well, which led to large retraction forces within the network and reduced the swelling ratio. The final swelling ratio at $24 \mathrm{~h}$ in deionized water was reported in Table 3 for SAP containing different crosslinking densities and AA group concentrations.

Fig. 5 indicates that the absorption kinetics of the anionic SAP immersed in the cement filtrate displayed fast absorption immediately followed by fast fluid release. The initial absorption is higher with higher anionic group density. The fast fluid release was probably caused by $\mathrm{Ca}^{2+}$ ions complexing with the anionic groups in the network, which leads to an increase of the effective crosslinking density and shrinkage of the SAP network $[22,28,36]$. As a result, additional uptake of the solution is blocked and swelling is reduced. This is the reason why the higher the molar ratio of AA/ANa in the network, the more the SAP release water. For the same reason, zwitterionic SAP and AM-based SAP showed less or even no fluid release.

The absorption of the anionic SAP (A73, A55, A37 and A37_5) was much lower in the cement filtrate (see Fig. 5) than in deionized water (see Fig. 3). The reason is a general screening of the charges of the SAP and reduction of the osmotic pressure that causes swelling by the dissolved ions. In addition, the presence of the divalent $\mathrm{Ca}^{2+}$ ions in cement filtrate fundamentally changes the absorption behaviour of anionic SAP [24]. The carboxylic group of the polymer complexes the $\mathrm{Ca}^{2+}$ ions in a stable way and the efficient anionic charge density inside the SAP diminishes $[22,25]$. The now apparently uncharged polymer chains experience a considerably lower osmotic pressure than uncomplexed chains and as a consequence the absorption capacity is tremendously diminished. This effect of $\mathrm{Ca}^{2+}$ complexation is strongly pronounced in SAP with high anionicity. For example, with the same crosslinking density, the absorption at $24 \mathrm{~h}$ is decreased by almost $100 \%$ in cement filtrate compared to deionized water for SAP A73 and by almost 90\% for SAP A37. Fig. 3 and Fig. 5 show that, on the contrary, cement filtrate has a limited influence on the absorption of zwitterionic SAP, which decreases only by $44 \%$ compared to deionized water. This reduction of absorption can be explained by the decrease of the osmotic pressure. 
On the other hand, unlike in the anionic SAP, in zwitterionic SAP the general screening charges by the dissolved ions in the cement filtrate cause an opposite effect [38, 68], leading to less dramatic reduction in absorption. The swelling characteristics of SAPs also depend on the attractive and repulsive forces between the various charged repeat units [66]. On the one hand, the anionic and cationic repeat units of SAPs attract each other and prevent the network from expanding. On the other hand, the repulsive forces between anionic-anionic and cationic-cationic repeat units cause the network to expand. The swelling characteristics of SAPs are determined by the net charge on the polymer network [67]. The zwitterionic SAP in water has extensive intra-associations (either intra-chain or intra-group type) [69]. These intraassociations will limit the swelling of the SAP. However, the ions from the cement filtrate break up these ionic associations between zwitterionic monomers by shielding the positive and negative charges, leading to the swelling enhancement [38, 69-71].The equilibrium swelling capacity of the zwitterionic SAPs increased as the ratio of anionic to cationic repeat units deviated from unity [67]. In this study, zwitterionic SAP has a higher molar ratio of AA monomer (anionic monomer) compared to the MAPTAC monomer (cationic monomer).

For the AM-based SAP samples, the absorptivity was even higher in cement filtrate than in deionized water (the absorptivity is $13.22 \pm 0.22 \mathrm{~g} / \mathrm{g}$ in deionized water and $25.34 \pm 0.67 \mathrm{~g} / \mathrm{g}$ in cement filtrate for SAP N). The AM-based SAP contain amide groups, which can be hydrolyzed to form carboxylic acid with hydrogen that can be deprotonated at high $\mathrm{pH}$ (above 12), making the polymer chains responsive to changes in $\mathrm{pH}$ or even to the type of ions present and their concentrations $[24,36]$.

Increasing the crosslinking density will also lead to decreased absorption of all SAP samples when immersed in cement filtrate, due to the increased bulk modulus. For SAP with the same anionic molar ratio monomer but different crosslinking density, the absorption of SAP also shows a significant decrease in cement filtrate compared with the absorption in deionized water (see Fig. 3 and Fig. 5). However, this decrease is more limited for SAP with higher crosslinking density. For example, the $24 \mathrm{~h}$ absorptivity is decreased by almost $90 \%$ in cement filtrate for SAP A37 and by $80 \%$ in SAP A37_5. The probable cause of this behavior is that the physical confinement imposed by the chemical crosslinks dominates the swelling response of the SAP particles compared to electrostatic-based confinement. The 

group concentrations is reported in Table 4.

\begin{tabular}{|c|c|}
\hline Sample & Absorption (g/g) \\
\hline SAP N & $13.22 \pm 0.22$ \\
\hline SAP A37 & $234.52 \pm 19.48$ \\
\hline SAP A55 & $320.59 \pm 12.29$ \\
\hline SAP A73 & $393.67 \pm 6.47$ \\
\hline SAP Z & $45.00 \pm 1.78$ \\
\hline SAP N_5 & $10.29 \pm 0.47$ \\
\hline SAP A37_5 & $85.10 \pm 5.66$ \\
\hline SAP Z_5 & $17.75 \pm 0.44$ \\
\hline
\end{tabular}

\begin{tabular}{|c|c|c|c|}
\hline \multirow{2}{*}{ Sample } & \multicolumn{3}{|c|}{ Absorption (g/g) } \\
\cline { 2 - 4 } & peak & $30 \mathrm{~min}$ & $24 \mathrm{~h}$ \\
\hline SAP N & - & $12.87 \pm 0.13$ & $21.65 \pm 0.29$ \\
\hline SAP A37 & $31.80 \pm 1.56$ & $27.89 \pm 0.92$ & $20.48 \pm 0.41$ \\
\hline SAP A55 & $36.81 \pm 1.47$ & $27.13 \pm 1.15$ & $12.02 \pm 0.46$ \\
\hline SAP A73 & $38.89 \pm 1.25$ & $27.84 \pm 2.23$ & $5.91 \pm 0.84$ \\
\hline SAP Z & $18.59 \pm 0.10$ & $18.35 \pm 0.26$ & $17.07 \pm 1.32$ \\
\hline SAP N_5 & - & $11.51 \pm 1.38$ & $15.45 \pm 0.49$ \\
\hline SAP A37_5 & $25.28 \pm 1.33$ & $21.61 \pm 0.84$ & $14.53 \pm 1.26$ \\
\hline SAP Z_5 & $14.97 \pm 0.84$ & $14.13 \pm 1.37$ & $13.83 \pm 1.33$ \\
\hline
\end{tabular}




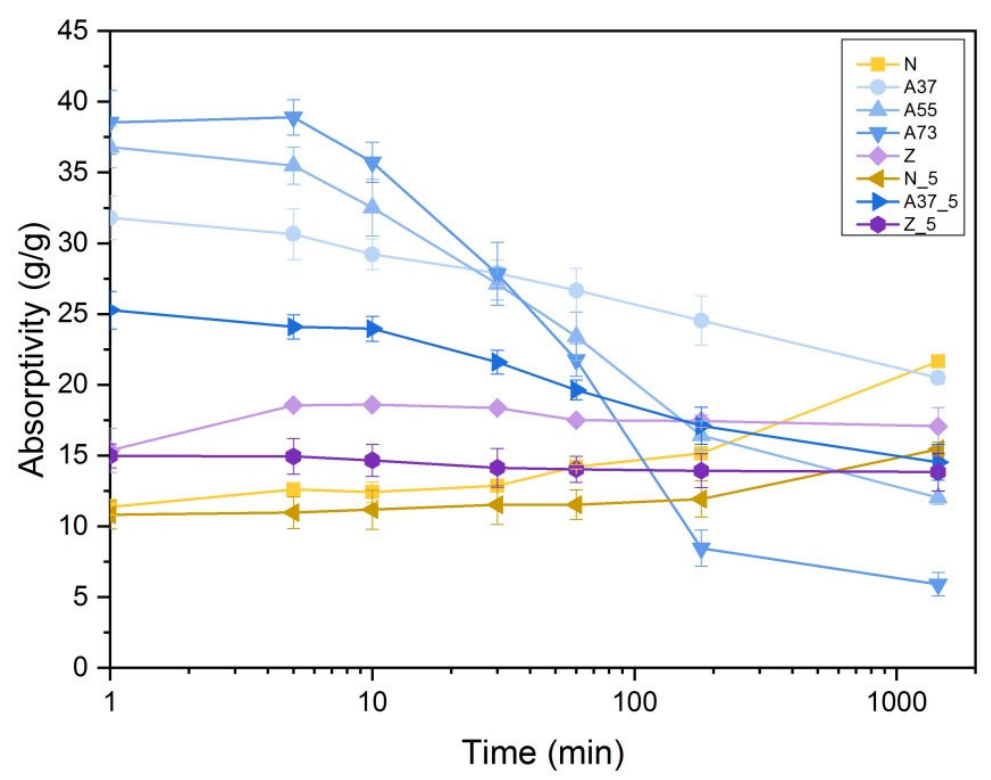

Fig. 5. Absorption of SAP in cement filtrate:

The hydration kinetics of cement pastes with and without different SAP types were investigated by using isothermal calorimetry (see Fig.6 and Fig. 7). As can be seen from the comparison of R and R1 in Fig. 6, a dormant period of 3-4 $\mathrm{h}$ is followed by a main heat rate peak at either 15 or $18 \mathrm{~h}$, respectively. For the pastes without SAP, the dormant period and the main heat release peak are delayed as $w / c$ is increased. The height of the main peaks slightly reduces with higher w/c, while the cumulative heat of hydration increases with w/c. The results are in good agreement with the results reported in previous studies $[72,73]$.

The main peaks of pastes with SAP (see Fig. 6a and Fig. 7a) are slightly lower and appear earlier compared to R1 with the same total w/c. This finding can be explained by the desorption kinetics of SAP. The entrained water introduced by SAP is then gradually released as pores in cement paste are emptied by chemical shrinkage and capillary forces build up $[18,74,75]$. The alkali metal ions $\left(\mathrm{K}^{+}\right.$and $\mathrm{Na}^{+}$) that come into solution after the first minutes, when the SAP are already swollen, would increase the concentration in the pore solution $[75,76]$. Therefore, the pastes with SAP show earlier main peaks compared to the reference paste R1 with the same total w/c. On the other hand, the main peaks of pastes 
with SAP are delayed compared to the reference paste R. One possibility is that some alkali ions were likely taken up by the SAP initially $[36,77]$. Thus, the initial alkali ions concentration in the pore solution was diluted and the main hydration peak was retarded. It is noticed that this retardation is lower than the retardation observed when the w/c is increased [76].

It can also be seen from Fig. 6a and 7a that the main hydration peak of AM-based and zwitterionic SAP appear slightly earlier than that of anionic SAP. One possible reason is that the carboxylic groups of anionic SAP complexes the $\mathrm{Ca}^{2+}$ ions in a stable way due to high AA, which makes anionic SAP have stronger alkali ions absorption. The dilution of initial alkali ions concentration is more obvious for anionic SAP. Another possible reason is that the fast liquid release after initial absorption of anionic SAP also contributes to the dilution of the pore solution. Therefore, the main cement hydration peaks with AM-based and zwitterionic SAP appear slightly earlier compared to anionic SAP.

Fig. $6 \mathrm{~b}$ and Fig. $7 \mathrm{~b}$ show that all pastes containing SAP reach higher cumulative hydration heat values than the reference paste R. The cumulative heat of hydration of pastes with SAP exceeds that of the reference paste R after about $24 \mathrm{~h}$. This is in good agreement with a previous study [75]. The hydration heat values of pastes with anionic SAP show no obvious difference with the reference paste R1 with the same w/c during 3 days. The hydration heat values of pastes with AM-based and zwitterionic SAP also show no obvious difference with the reference paste R1 with the same w/c during the first $36 \mathrm{~h}$ and slightly lower values after 3 days. The stable absorption of AM-based and zwitterionic SAP in pore solution may be the cause of this small difference. 

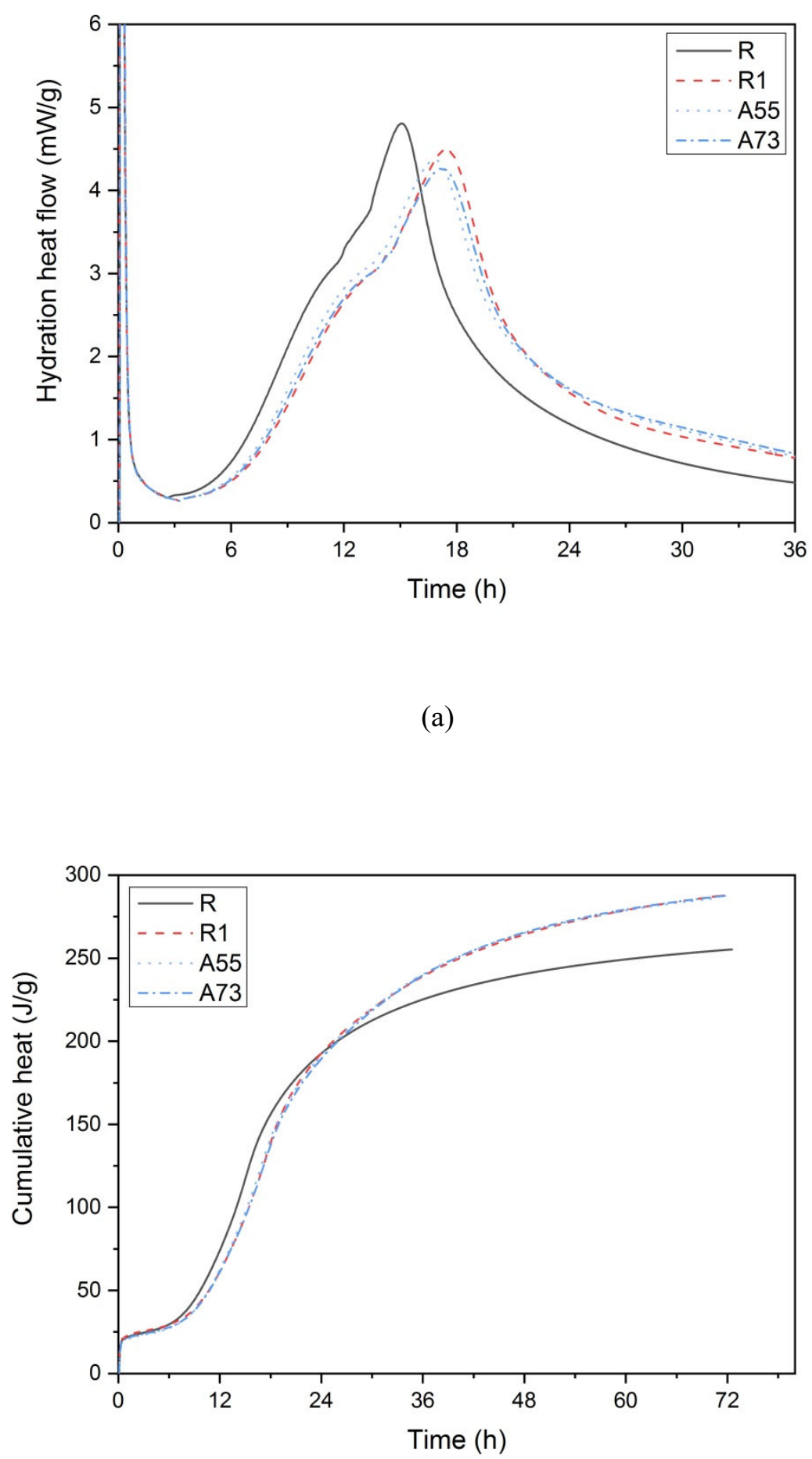

423 Fig. 6. Effects of anionic SAP on cement hydration kinetics: (a) hydration heat release rate (until 


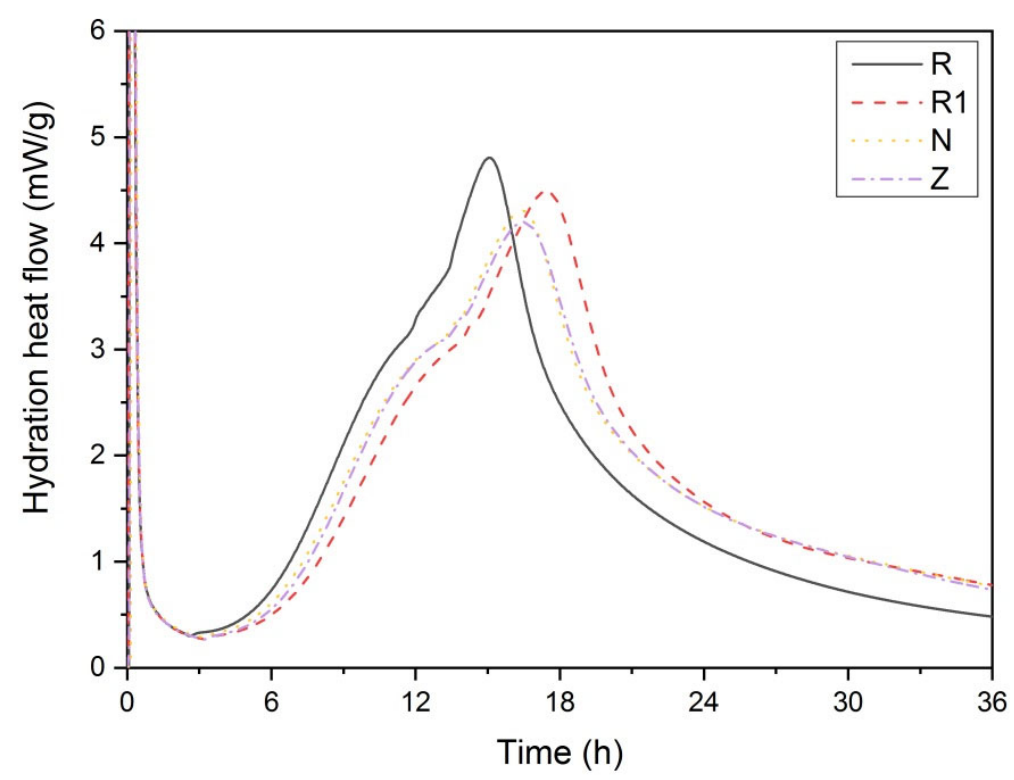

425

(a)

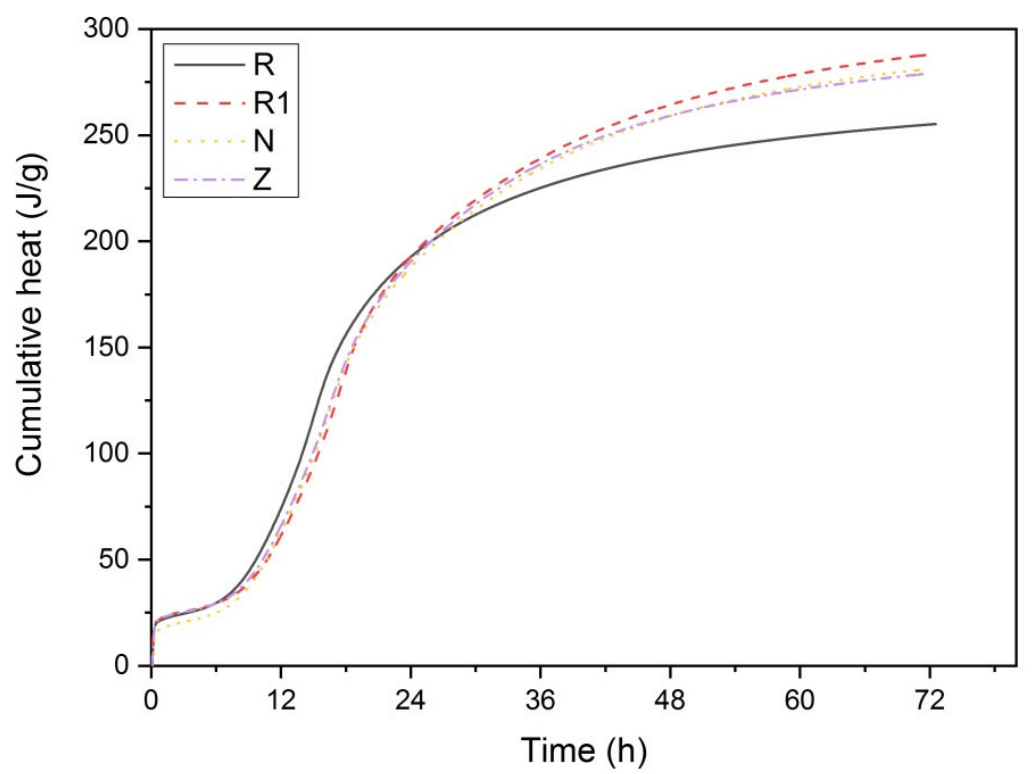

427

(b)

Fig. 7. Effects of AM-based (SAP N) and zwitterionic (SAP Z) SAP on hydration kinetics: (a) 


\subsection{Autogenous deformation}

Fig. 8-10 shows the linear strain of cement pastes with SAP of different chemical structure. The strain was zeroed at the time instant when the scatter of the deformation rates of duplicate samples reached a constant, low level [49]. Each curve shows the average of two measurements.

The reference mixtures R and R1 continued to shrink significantly over time (see Fig. 8). As expected, mixture $\mathrm{R}$ with lower w/c shows higher autogenous shrinkage. When compared to the SAP-free reference paste R and R1, adding any type of SAP reduced the autogenous shrinkage. This is worth noting considering that all mixtures with SAP had the same total $\mathrm{w} / \mathrm{c}(0.354)$ as the paste R1. As observed previously [78], in this w/c range autogenous shrinkage was not eliminated by just increasing free water (corresponding to a difference in w/c between R and R1: from 0.300 to 0.354 ), it was only slightly reduced.

Fig. 8 shows that anionic SAP were able to induce rapid expansion during the first day and continuous, slow expansion after that. According to Krafcik and Erk [32], if the SAP begin releasing the absorbed pore solution fluid around initial set, the fluid will fill the capillary pores next to the SAP, from which it is transported further into the still highly permeable matrix. This mechanism of water redistribution from the SAP had been already proposed by Wyrzykowski et al. [74]. On the contrary, according to Schröfl et al. [28] SAP with high AA and fast fluid release are only efficient as internal curing agents at very early age, until all the fluid is released. In the present study, SAP with high AA molar ratio led to fast fluid release in pore solution, but also showed excellent internal curing performance. Our new results agree with [32] and may confirm the mechanism of fluid release and redistribution already proposed in [74].

Fig. 9 shows the autogenous deformation of pastes with AM-based and zwitterionic SAP. Both AMbased and zwitterionic SAP show stable storage (i.e. no release of the absorbed solution) in cement pore solution (see Fig. 5). The addition of both SAP types also reduced autogenous shrinkage significantly compared to the reference pastes. The paste with SAP Z exhibited intense expansion during the first day 
and slight expansion later, while the paste with SAP N exhibited smaller expansion during the first day and slow shrinkage later on. Free desorption of pore solution by SAP is apparently sufficient to eliminate shrinkage and induce expansion already in the first hours after final set. Among the absorption of SAP examined in cement filtrate in this study, the sequence of absorption before 30 min was A73 > A55 > A37 $>\mathrm{Z}>\mathrm{N}$ (see Fig. 5). This order is almost the same as the initial expansion of paste containing SAP, with the only exception of SAP Z. It is worth noting that all mixtures with SAP have the same amount of entrained water, which means that the dosage of different SAP types is different. Whereas the dosage of SAP with high absorption at $30 \mathrm{~min}$ is lower than that of SAP with low absorption, the SAP with higher absorption show better internal curing performance. Good internal curing performance is characterized by steady, moderate expansion that does not turn into shrinkage in the period of testing. As the initial particle size distributions in the dry state of all SAP types are very similar, it appears that larger internal curing reservoirs introduced by SAP with high absorption demonstrate better internal between $\mathrm{N}$ and $\mathrm{N} \_5$ was observed. The reason may also be caused by the reservoir size introduced by SAP. The absorption of $\mathrm{A} 37$ and $\mathrm{Z}$ decrease with increasing crosslinking density, but the absorption of $\mathrm{N}$ and $\mathrm{N} \_5$ was similar. This is consistent with the results obtained above.

The origin of the often observed early-age expansion in cementitious materials with internal curing may be caused by crystallization pressure of hydration products. For the case of SAP, it is possible that the portlandite formation was discussed as the main reason for the early-age expansions observed. The pore solution saturation level has been related to the size of crystals and the magnitude of crystallization modification of portlandite formation may play a decisive role in early age expansion, while ettringite precipitation might also contribute $[34,79]$. The phenomenon of early-age expansion was previously reported and discussed by Sant et al. and Zuo et al. $[34,80]$. Although no SAP was used in those studies, stresses. Considering that pore fluid absorption by the SAP likely increases the saturation level, this may contribute to the expansion of pastes with SAP. 


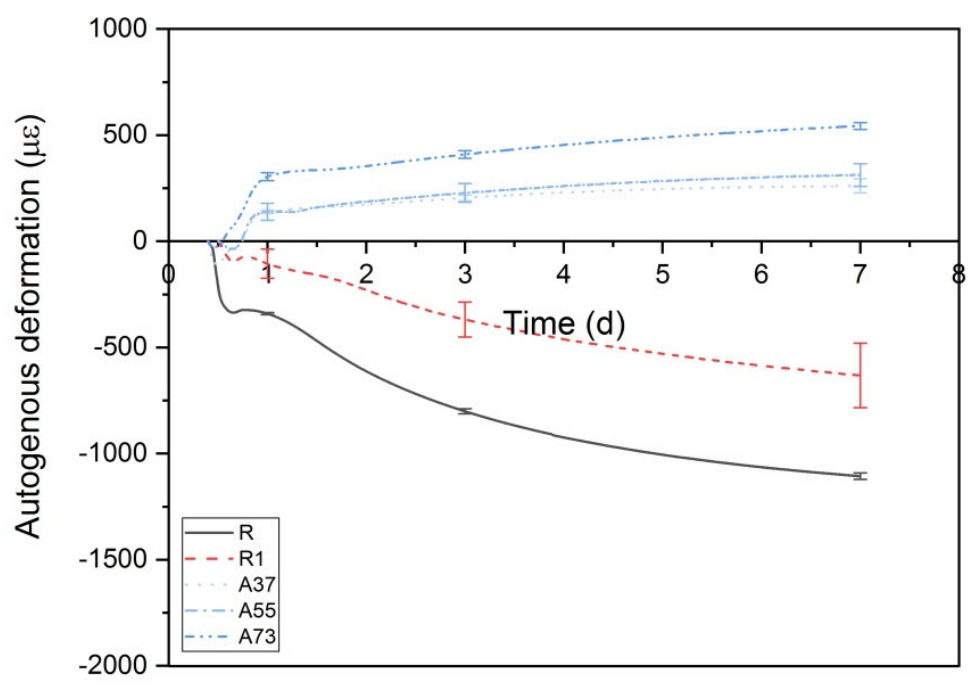

486 Fig. 8. Autogenous deformation of pastes with anionic SAP. The error bars represent the standard deviation (shown only at chosen time points).

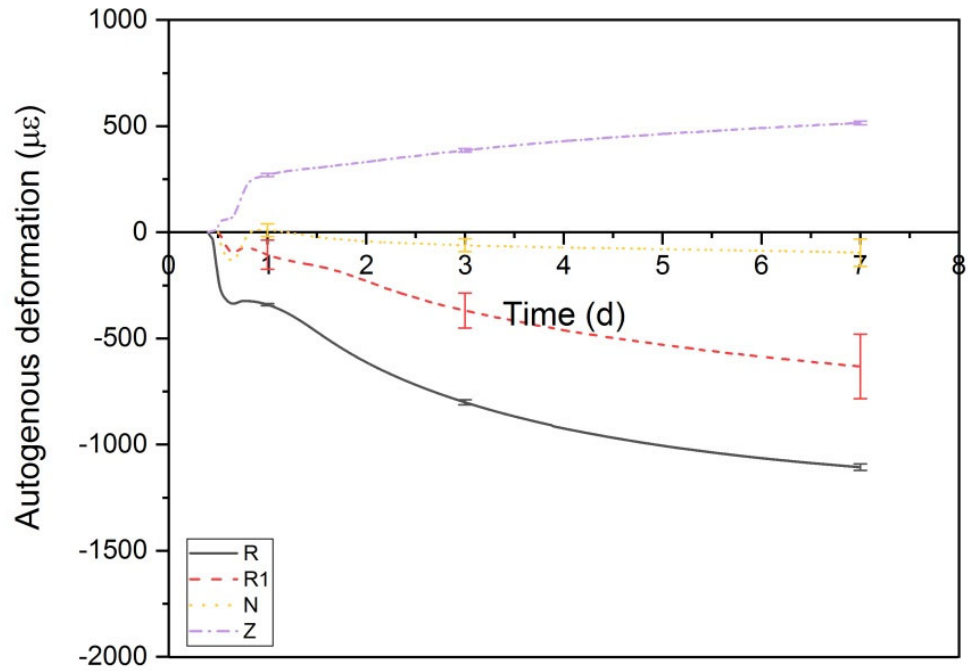
represent the standard deviation (shown only at chosen time points). 


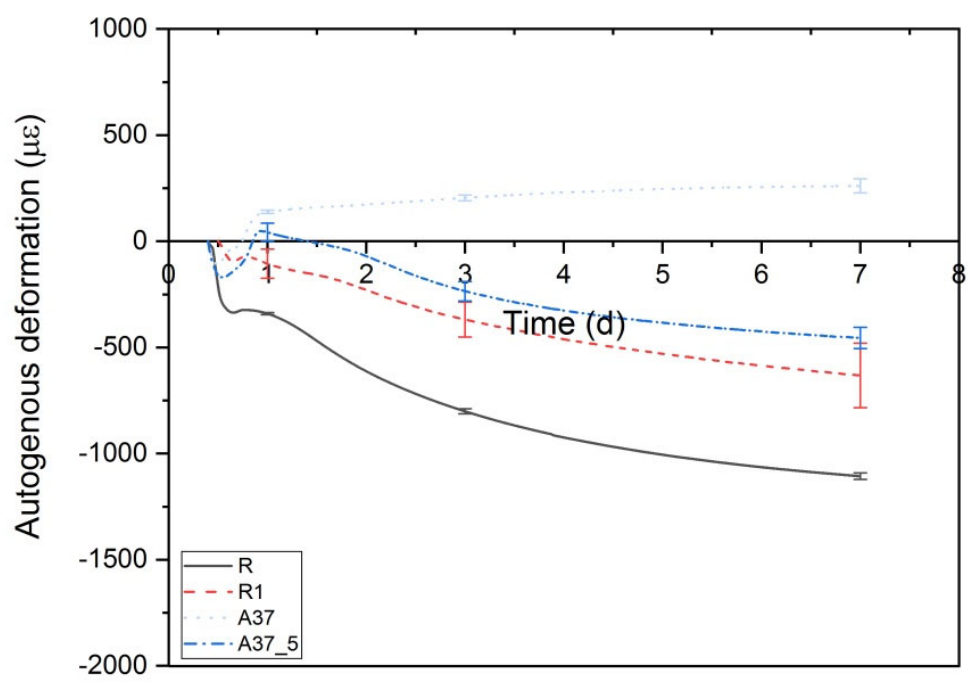

491

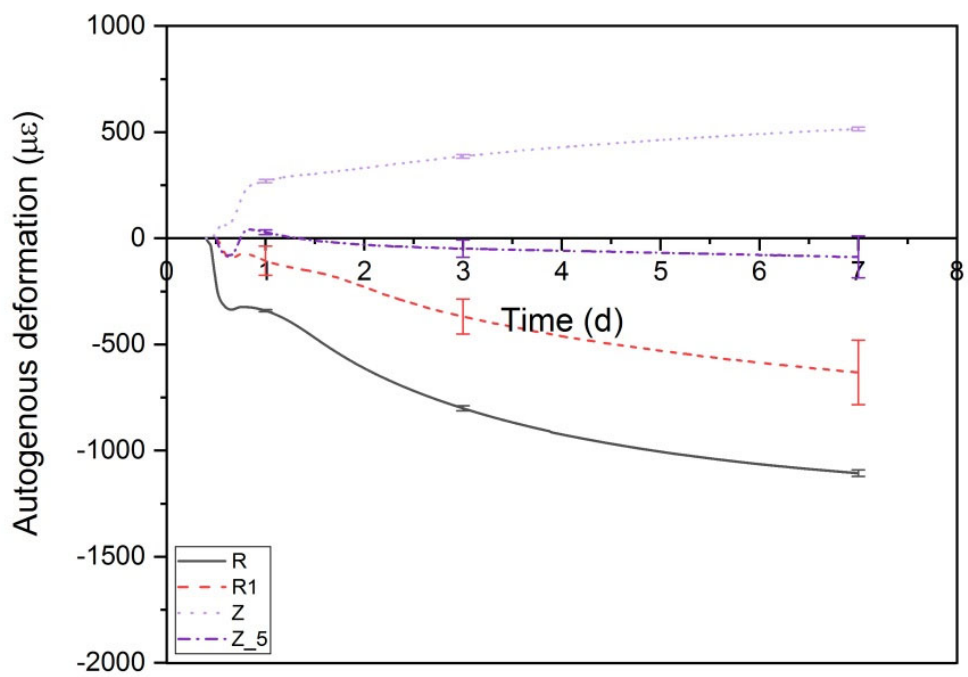

493

(b) 


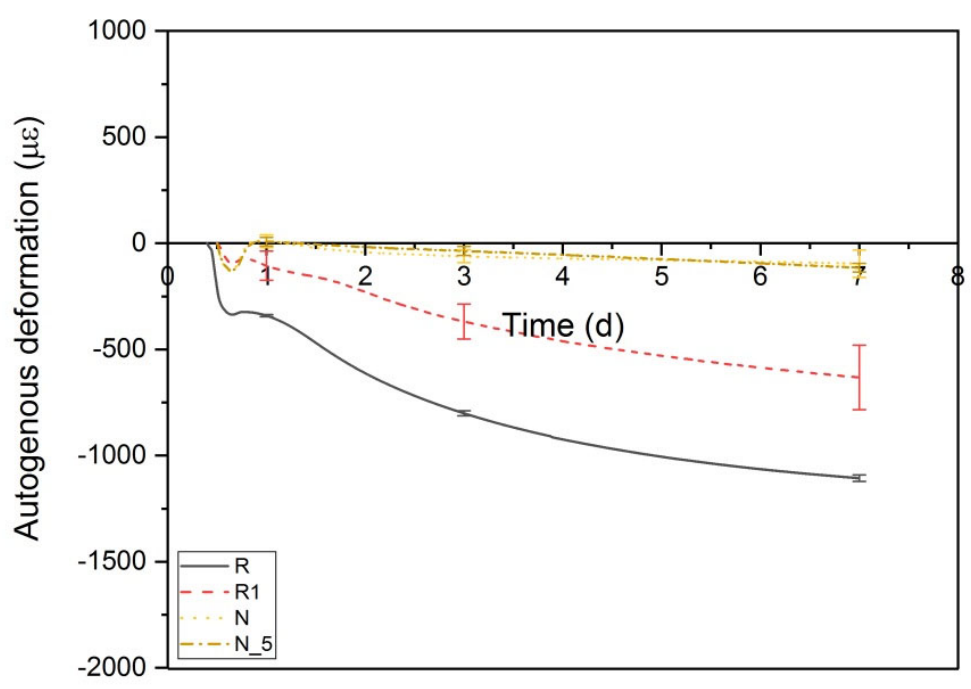
zwitterionic SAP; (c) AM-based SAP. The error bars represent the standard deviation (shown only at chosen time points).

Fig. 11 shows the compressive strength of cement pastes with or without SAP as a function of age. The basic $\mathrm{w} / \mathrm{c}$ is 0.300 , while the $\mathrm{w}_{\mathrm{e}} / \mathrm{c}$ is 0.054 for all pastes with internal curing. As expected, the reference paste $\mathrm{R}$ with $\mathrm{w} / \mathrm{c}=0.300$ showed higher strength than $\mathrm{R} 1 \mathrm{with} \mathrm{w} / \mathrm{c}=0.354$ and the compressive strength of all pastes increased with age. According to previous studies, the effect of SAP addition on the compressive strength of concrete could be a counterbalanced result of several factors $[15,81]$. On the one hand, the large voids introduced by SAP after releasing water may in general have negative influence on the compressive strength [82]. In this regard, the size of the SAP voids and portlandite precipitation into the voids may play a role. On the other hand, cement hydration may be enhanced by the addition of SAP that provides extra curing water [75].

In this study, all pastes with SAP showed lower compressive strength compared with the reference paste 
types of SAP, as the initial porosity of paste $\mathrm{R}$ is lower and additional voids are introduced by SAP particles for mixtures with SAP. On the other hand, two way analysis of variance (ANOVA, with SAP type and age as factors) suggested no significant difference (P-value of 0.18 ) between R1 and the pastes with different SAP types at $3 \mathrm{~d}$ and $7 \mathrm{~d}$. This is also expected considering that the total $\mathrm{w} / \mathrm{c}$ is the same, the initial porosity is the same and the final degree of hydration is expected to be similar. However, the compressive strength of pastes with different types of SAP at $1 \mathrm{~d}$ increased by $11-27 \%$ compared to that of the reference R1, with the only exception of SAP N. This may be caused by the acceleration of hydration observed in isothermal calorimetry (see Fig. 6 and Fig. 7) and discussion above. Although small differences exist between the pastes with different SAP, no significant trend could be seen regarding the SAP type (anionic, AM-based or zwitterionic) when all ages are considered together (as shown by a two-way ANOVA with SAP type and age as factors; the P-value for the type factor was > 0.3). When only the age of $3 \mathrm{~d}$ and $7 \mathrm{~d}$ are considered, the type of SAP becomes moderately significant (according to ANOVA, with P-value of 0.02). Slightly lower strength were found at these ages for pastes with zwtterionic SAP.

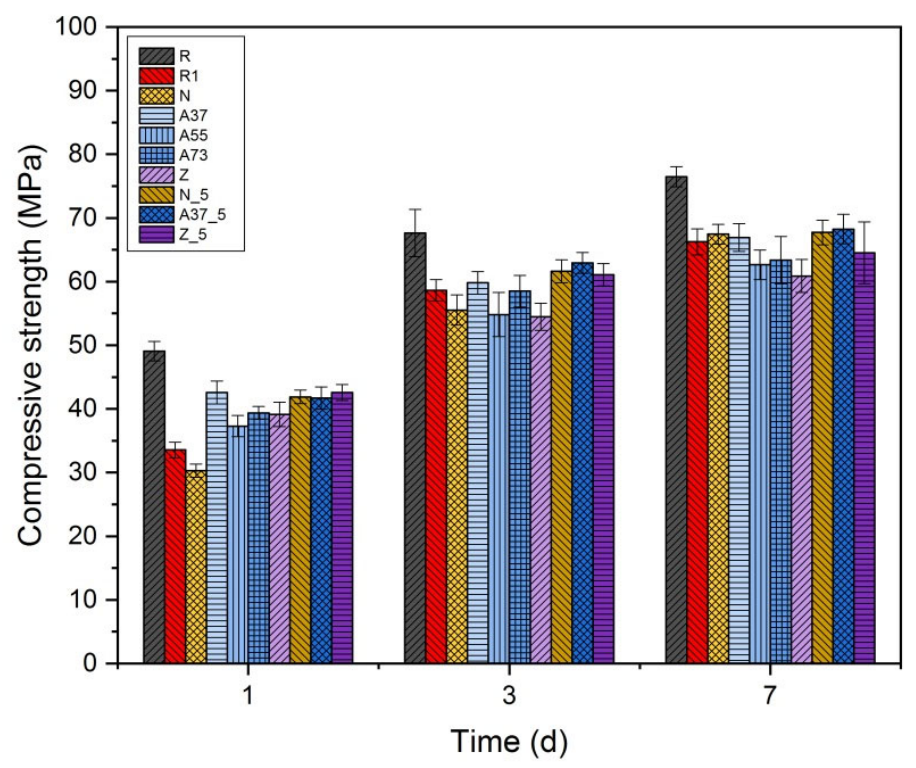




\section{Conclusions}

This study investigated the effect of the chemical structure of SAP on their absorption capacity and on the efficiency of internal curing. SAP with different density of ionic groups, different types of ionic groups and different crosslinking density were synthesized. The main experimental outcomes are as follows:

(1) The absorption of SAP in cement filtrate was strongly decreased in comparison to deionized water. SAP with high density of anionic groups showed rapid absorption in cement filtrate, immediately followed by desorption. SAP with low density of anionic groups showed more limited desorption in cement filtrate. The liquid desorption ranged from 35 to $85 \%$ of the maximum absorption. No desorption was observed with SAP of only non-ionic groups or both anionic and cationic groups in cement filtrate.

(2) Increments in crosslinking density in ionic and zwitterionic SAP resulted in decreased equilibrium absorptivity both in deionized water and cement filtrate. On the contrary, increments in cross-linking density in non-ionic SAP had a small effect on the absorptivity. SAP with high crosslinking density were less sensitive to the solution environment.

(3) All SAP synthesized in this paper counteracted autogenous shrinkage, albeit to different extents. When the amount of entrained water was the same, SAP with high absorptivity before $30 \mathrm{~min}$ showed better internal curing performance. Contrary to some previous studies, also SAP with rapid liquid release after initial absorption in the teabag experiments were able to eliminate autogenous shrinkage. Zwitterionic SAP showed excellent internal curing performance.

(4) SAP with different chemical structures showed no significant negative influence on the compressive strength of cement pastes when the total water-to-cement ratios were the same as in a reference paste without SAP. Cement pastes with different types of SAP showed slightly higher compressive strength at 1 day compared to a reference paste with the same total w/c, while the compressive strengths are close to the reference paste at 7 days. 
Peihua Zhong gratefully acknowledges financial support from China Scholarship Council (CSC number: 201706090130). The authors thank Wenbin Wang and Qian Wang from Jiangsu Sobute New Materials Co., Ltd. for guidance in synthesizing SAP, Yiru Yan from Empa for help with FTIR spectra measurements, and Luigi Brunetti from Empa for help with isothermal calorimetry measurements.

\section{Reference}

[1] S. Zhutovsky, K. Kovler, A. Bentur, Revisiting the protected paste volume concept for internal curing of high-strength concretes, Cement and Concrete Research, 41 (2011) 981-986.

[2] Z.-n. Hu, Y.-1. Xie, J. Wang, Challenges and strategies involved in designing and constructing a 6 km immersed tunnel: A case study of the Hong Kong-Zhuhai-Macao Bridge, Tunnelling and underground space technology, 50 (2015) 171-177.

[3] J. Wen-yu, A. Ming-zhe, Y. Gui-ping, W. Jun-min, Study on reactive powder concrete used in the sidewalk system of the Qinghai-Tibet railway bridge, International Workshop on Sustainable Development and Concrete Technology, Beijing, China, 2004, pp. 333-338.

[4] B. Craeye, M. Geirnaert, G.D. Schutter, Super absorbing polymers as an internal curing agent for mitigation of early-age cracking of high-performance concrete bridge decks, Construction and Building Materials, 25 (2011) 1-13.

[5] H. Chen, M. Wyrzykowski, K. Scrivener, P. Lura, Prediction of self-desiccation in low water-tocement ratio pastes based on pore structure evolution, Cement and Concrete Research, 49 (2013) 38-47.

[6] P. Lura, O.M. Jensen, K. van Breugel, Autogenous shrinkage in high-performance cement paste: An evaluation of basic mechanisms, Cement and concrete research, 33 (2003) 223-232.

[7] P. Lura, K. van Breugel, I. Maruyama, Effect of curing temperature and type of cement on early-age shrinkage of high-performance concrete, Cement and Concrete Research, 31 (2001) 1867-1872. 
[8] O.M. Jensen, P.F. Hansen, Water-entrained cement-based materials: I. Principles and theoretical background, Cement and concrete research, 31 (2001) 647-654.

[9] P. Lura, Autogenous deformation and internal curing of concrete, TU Delft, Delft University of Technology, 2003.

[10] S. Zhutovsky, K. Kovler, A. Bentur, Assessment of distance of water migration in internal curing of high-strength concrete, ACI SP-220 'Autogenous deformation of concrete'. Farmington Hills, Michigan, (2004) 181-197.

[11] O.M. Jensen, P. Lura, Techniques and materials for internal water curing of concrete, Materials and Structures, 39 (2006) 817-825.

[12] J. Liu, C. Shi, X. Ma, K.H. Khayat, J. Zhang, D. Wang, An overview on the effect of internal curing on shrinkage of high performance cement-based materials, Construction and Building Materials, 146 (2017) 702-712.

[13] P. Lura, M. Wyrzykowski, C. Tang, E. Lehmann, Internal curing with lightweight aggregate produced from biomass-derived waste, Cement and Concrete Research, 59 (2014) 24-33.

[14] M. Wyrzykowski, S. Ghourchian, S. Sinthupinyo, N. Chitvoranund, T. Chintana, P. Lura, Internal curing of high performance mortars with bottom ash, Cement and Concrete Composites, 71 (2016) 1-9.

[15] P. Lura, O.M. Jensen, S.-I. Igarashi, Experimental observation of internal water curing of concrete, Materials and Structures, 40 (2006) 211-220.

[16] S. Ghourchian, M. Wyrzykowski, P. Lura, M. Shekarchi, B. Ahmadi, An investigation on the use of zeolite aggregates for internal curing of concrete, Construction and Building Materials, 40 (2013) 135-144.

[17] O.M. Jensen, Use of superabsorbent polymers in concrete, Concrete international, 35 (2013) 48-52.

[18] O.M. Jensen, P.F. Hansen, Water-entrained cement-based materials: II. Experimental observations, 
[19] M. Wyrzykowski, S.-I. Igarashi, P. Lura, V. Mechtcherine, Recommendation of RILEM TC 260RSC: using superabsorbent polymers (SAP) to mitigate autogenous shrinkage, Materials and Structures, 51 (2018) 135.

[20] M.J. Zohuriaan-Mehr, K. Kabiri, Superabsorbent polymer materials: a review, Iranian polymer journal, 17 (2008) 451.

[21] P.J. Flory, Principles of polymer chemistry, Cornell University Press1953.

[22] Q. Zhu, C.W. Barney, K.A. Erk, Effect of ionic crosslinking on the swelling and mechanical response of model superabsorbent polymer hydrogels for internally cured concrete, Materials and Structures, 48 (2015) 2261-2276.

[23] X.P. Chen, G.R. Shan, J. Huang, Z.M. Huang, Z.X. Weng, Synthesis and properties of acrylic based superabsorbent, Journal of applied polymer science, 92 (2004) 619-624.

[24] P.B. Jar, Y.S. Wu, Effect of counter-ions on swelling and shrinkage of polyacrylamide-based ionic gels, Polymer, 38 (1997) 2557-2560.

[25] S.-H. Kang, S.-G. Hong, J. Moon, Absorption kinetics of superabsorbent polymers (SAP) in various cement-based solutions, Cement and Concrete Research, 97 (2017) 73-83.

[26] H.X.D. Lee, H.S. Wong, N.R. Buenfeld, Effect of alkalinity and calcium concentration of pore solution on the swelling and ionic exchange of superabsorbent polymers in cement paste, Cement and Concrete Composites, 88 (2018) 150-164.

[27] C. Chang, B. Duan, J. Cai, L. Zhang, Superabsorbent hydrogels based on cellulose for smart swelling and controllable delivery, European Polymer Journal, 46 (2010) 92-100.

[28] C. Schröfl, V. Mechtcherine, M. Gorges, Relation between the molecular structure and the efficiency of superabsorbent polymers (SAP) as concrete admixture to mitigate autogenous shrinkage, Cement and Concrete Research, 42 (2012) 865-873. 
[29] A. Pourjavadi, S.M. Fakoorpoor, P. Hosseini, A. Khaloo, Interactions between superabsorbent polymers and cement-based composites incorporating colloidal silica nanoparticles, Cement and Concrete Composites, 37 (2013) 196-204.

[30] W. Siriwatwechakul, J. Siramanont, W. Vichit-Vadakan, Superabsorbent polymer structures, International RILEM Conference on Use of Superabsorbent Polymers and Other New Additives in Concrete, RILEM Publications SARL, 2010, pp. 253-262.

[31] Y. Bao, J. Ma, N. Li, Synthesis and swelling behaviors of sodium carboxymethyl cellulose-g-poly (AA-co-AM-co-AMPS)/MMT superabsorbent hydrogel, Carbohydrate Polymers, 84 (2011) 76-82.

[32] M.J. Krafcik, K.A. Erk, Characterization of superabsorbent poly(sodium-acrylate acrylamide) hydrogels and influence of chemical structure on internally cured mortar, Materials and Structures, 49 (2016) 4765-4778.

[33] P. Lura, B. Lothenbach, C. Miao, G. Ye, H. Chen, Influence of pore solution chemistryon shrinkage of cement paste, The 50-year Teaching and Research Anniversary of Prof. Sun Wei on Advances in Civil Engineering Materials, (2010) 191-200.

[34] W. Zuo, P. Feng, P. Zhong, Q. Tian, N. Gao, Y. Wang, C. Yu, C. Miao, Effects of novel polymertype shrinkage-reducing admixture on early age autogenous deformation of cement pastes, Cement and Concrete Research, 100 (2017) 413-422.

[35] J. Siramanont, W. Vichit-Vadakan, W. Siriwatwechakul, The impact of SAP structure on the effectiveness of internal curing, International RILEM Conference on Use of Superabsorbent Polymers and Other New Additives in Concrete, RILEM Publications SARL, 2010, pp. 243-252.

[36] W. Siriwatwechakul, J. Siramanont, W. Vichit-Vadakan, Behavior of Superabsorbent Polymers in Calcium- and Sodium-Rich Solutions, Journal of Materials in Civil Engineering, 24 (2012) 976-980.

[37] W.F. Lee, Y.L. Huang, Superabsorbent polymeric materials IX: Effect of cationic structure on swelling behavior of crosslinked poly (sodium acrylate - co - cationic monomers) in aqueous salt solutions, Journal of applied polymer science, 81 (2001) 1827-1837. 
[38] A. Pourjavadi, M. Kheirabadi, M.J. Zohuriaan-Mehr, K. Kabiri, Antipolyelectrolyte superabsorbing nanocomposites: Synthesis and properties, Journal of Applied Polymer Science, 114 (2009) 3542-3547.

[39] C. Schroefl, V. Mechtcherine, P. Vontobel, J. Hovind, E. Lehmann, Sorption kinetics of superabsorbent polymers (SAPs) in fresh Portland cement-based pastes visualized and quantified by neutron radiography and correlated to the progress of cement hydration, Cement and Concrete Research, 75 (2015) 1-13.

[40] D. Snoeck, O.M. Jensen, N. De Belie, The influence of superabsorbent polymers on the autogenous shrinkage properties of cement pastes with supplementary cementitious materials, Cement and Concrete Research, 74 (2015) 59-67.

[41] G. Wang, M. Li, X. Chen, Inverse suspension polymerization of sodium acrylate, Journal of applied polymer science, 65 (1997) 789-794.

[42] H. Omidian, S. Hashemi, P. Sammes, I. Meldrum, Modified acrylic-based superabsorbent polymers (dependence on particle size and salinity), Polymer, 40 (1999) 1753-1761.

[43] T. Cai, Z. Yang, H. Li, H. Yang, A. Li, R. Cheng, Effect of hydrolysis degree of hydrolyzed polyacrylamide grafted carboxymethyl cellulose on dye removal efficiency, Cellulose, 20 (2013) 26052614.

[44] Q. Ma, P.J. Shuler, C.W. Aften, Y. Tang, Theoretical studies of hydrolysis and stability of polyacrylamide polymers, Polymer Degradation and Stability, 121 (2015) 69-77.

[45] C.A. Schneider, W.S. Rasband, K.W. Eliceiri, NIH Image to ImageJ: 25 years of image analysis, Nature methods, 9 (2012) 671.

[46] D. Snoeck, C. Schröfl, V. Mechtcherine, Recommendation of RILEM TC 260-RSC: testing sorption by superabsorbent polymers (SAP) prior to implementation in cement-based materials, Materials and Structures, 51 (2018) 116.

[47] V. Mechtcherine, D. Snoeck, C. Schröfl, N. De Belie, A.J. Klemm, K. Ichimiya, J. Moon, M. Wyrzykowski, P. Lura, N. Toropovs, Testing superabsorbent polymer (SAP) sorption properties prior 
to implementation in concrete: results of a RILEM Round-Robin Test, Materials and Structures, 51 (2018) 28 .

[48] A. ASTM, C1698-09 Standard test method for autogenous strain of cement paste and mortar, ASTM International, West Conshohocken, PA, (2009).

[49] M. Wyrzykowski, Z. Hu, S. Ghourchian, K. Scrivener, P. Lura, Corrugated tube protocol for autogenous shrinkage measurements: Review and statistical assessment, Materials and Structures, 50 (2017) 57.

[50] J. Zhang, A. Li, A. Wang, Synthesis and characterization of multifunctional poly(acrylic acid-coacrylamide)/sodium humate superabsorbent composite, Reactive and Functional Polymers, 66 (2006) 747-756.

[51] W. Zou, L. Yu, X. Liu, L. Chen, X. Zhang, D. Qiao, R. Zhang, Effects of amylose/amylopectin ratio on starch-based superabsorbent polymers, Carbohydrate Polymers, 87 (2012) 1583-1588.

[52] A. Mignon, G.-J. Graulus, D. Snoeck, J. Martins, N. De Belie, P. Dubruel, S. Van Vlierberghe, pHsensitive superabsorbent polymers: a potential candidate material for self-healing concrete, Journal of Materials Science, 50 (2014) 970-979.

[53] H.-A. Kalaleh, Y. Atassi, Up-Scalable Synthesis of High Porous Superabsorbent Polymer via Alkaline Hydrolysis of Acrylamide using Microwave Irradiation: Application in Agriculture, Journal of Materials and Environmental Sciences, 9 (2018) 955-963.

[54] M. Said, Y. Atassi, M. Tally, H. Khatib, Environmentally Friendly Chitosan-g-poly(acrylic acidco-acrylamide)/Ground Basalt Superabsorbent Composite for Agricultural Applications, Journal of Polymers and the Environment, 26 (2018) 3937-3948.

[55] M. Chi, C. Liu, J. Shen, Z. Dong, Z. Yang, L. Wang, Antibacterial Superabsorbent Polymers from Tara Gum Grafted Poly(Acrylic acid) Embedded Silver Particles, Polymers, 10 (2018) 945. 
[56] Ö. Ceylan, M.A. Kaya, A. Sarac, Preparation of partially neutralized poly(acrylic acid) microspheres via inverse pickering suspension polymerization, Polymer Engineering \& Science, 59 (2019) 162-169.

[57] A. Salerno, R. Borzacchiello, P.A. Netti, Pore structure and swelling behavior of porous hydrogels prepared via a thermal reverse-casting technique, Journal of Applied Polymer Science, 122 (2011) 36513660.

[58] J. Li, K. Zhang, M. Zhang, Y. Fang, X. Chu, L. Xu, Fabrication of a fast - swelling superabsorbent resin by inverse suspension polymerization, Journal of Applied Polymer Science, 135 (2018) 46142.

[59] X. Li, H. Zheng, B. Gao, C. Zhao, Y. Sun, UV-initiated polymerization of acid- and alkali-resistant cationic flocculant P(AM-MAPTAC): Synthesis, characterization, and application in sludge dewatering, Separation and Purification Technology, 187 (2017) 244-254.

[60] B. Wang, F. Wang, Y. Kong, Z. Wu, R.-M. Wang, P. Song, Y. He, Polyurea-crosslinked cationic acrylate copolymer for antibacterial coating, Colloids and Surfaces A: Physicochemical and Engineering Aspects, 549 (2018) 122-129.

[61] G. Sen, S. Pal, Polyacrylamide Grafted Carboxymethyl Tamarind (CMT-g-PAM): Development and Application of a Novel Polymeric Flocculant, Macromolecular Symposia, 277 (2009) 100-111.

[62] L. Lin, Y. Luo, X. Li, Synthesis of Diblock Polyampholyte PAMPS-b-PMAPTAC and Its Adsorption on Bentonite, Polymers, 11 (2018) 49.

[63] T. Stutzmann, B. Siffert, Contribution to the adsorption mechanism of acetamide and polyacrylamide on to clays, Clays and Clay Minerals, 25 (1977) 392-406. sodium montmorillonite: Relation between adsorption, $\xi$ potential, turbidity, enthalpy of adsorption data and 13C-NMR in aqueous solution, Journal of colloid and interface science, 124 (1988) 515-527. 
[66] A.E. English, T. Tanaka, E.R. Edelman, Polymer and solution ion shielding in polyampholytic hydrogels, Polymer, 39 (1998) 5893-5897.

724

[67] N.B. Shukla, S. Rattan, G. Madras, Swelling and dye-adsorption characteristics of an amphoteric superabsorbent polymer, Industrial \& Engineering Chemistry Research, 51 (2012) 14941-14948.

[68] W.F. Lee, Y.M. Tu, Superabsorbent polymeric materials. VI. Effect of sulfobetaine structure on swelling behavior of crosslinked poly (sodium acrylate - co - sulfobetaines) in aqueous salt solutions, Journal of applied polymer science, 72 (1999) 1221-1232.

[69] K. Kabiri, S. Faraji - Dana, M.J. Zohuriaan - Mehr, Novel sulfobetaine - sulfonic acid - contained superswelling hydrogels, Polymers for advanced technologies, 16 (2005) 659-666.

[70] W. Cai, R.B. Gupta, Thermosensitive and ampholytic hydrogels for salt solution, Journal of applied polymer science, 88 (2003) 2032-2037.

[71] D. Han, R. Letteri, D. Chan-Seng, T. Emrick, H. Tu, Examination of zwitterionic polymers and gels subjected to mechanical constraints, Polymer, 54 (2013) 2887-2894.

[72] D.M. Kirby, J.J. Biernacki, The effect of water-to-cement ratio on the hydration kinetics of tricalcium silicate cements: testing the two-step hydration hypothesis, Cement and Concrete Research, $42(2012)$ 1147-1156.

[73] X. Pang, The effect of water-to-cement ratio on the hydration kinetics of Portland cement at different temperatures, The 14th International Congress on the Chemistry of Cement, October, 2015, pp. 13-16.

[74] M. Wyrzykowski, P. Lura, F. Pesavento, D. Gawin, Modeling of Water Migration during Internal Curing with Superabsorbent Polymers, Journal of Materials in Civil Engineering, 24 (2012) 1006-1016. [75] J. Justs, M. Wyrzykowski, F. Winnefeld, D. Bajare, P. Lura, Influence of superabsorbent polymers on hydration of cement pastes with low water-to-binder ratio, Journal of Thermal Analysis and Calorimetry, 115 (2013) 425-432. 
[76] J. Justs, M. Wyrzykowski, D. Bajare, P. Lura, Internal curing by superabsorbent polymers in ultrahigh performance concrete, Cement and Concrete Research, 76 (2015) 82-90.

748 [77] S.-H. Kang, S.-G. Hong, J. Moon, Importance of monovalent ions on water retention capacity of 749 superabsorbent polymer in cement-based solutions, Cement and Concrete Composites, 88 (2018) 64-72. [78] P. Lura, F. Durand, O.M. Jensen, Autogenous strain of cement pastes with superabsorbent polymers, International RILEM Conference on Volume Changes of Hardening Concrete: Testing and Mitigation, RILEM Publications SARL, 2006, pp. 65. hydroxide on volume changes in cementitious materials, Cement and Concrete Research, 42 (2012) $1447-1455$. expansions induced in cementitious materials containing shrinkage reducing admixtures, Cement and concrete research, 41 (2011) 218-229. high-strength concrete, Materials and Structures, 48 (2014) 2741-2758. 